\title{
Grain Size Influence on the Compaction Aptitude and the Bearing Strength of the Gravel Lateritic Soils
}

\author{
Baye Oumar Diop ${ }^{*}$, Ignace Gbaguidi2, Papa Goumbo Lo²,3, Aminata Cisse ${ }^{4}$, Seynabou Sène³, \\ Makhaly $\mathrm{Ba}^{5}$
}

${ }^{1}$ École Supérieure Polytechnique, Université Cheikh Anta Diop, Dakar, Senegal

${ }^{2}$ Institut des Sciences de la Terre, Faculté des Sciences et Techniques, Université Cheikh Anta Diop, Dakar, Senegal

${ }^{3}$ Centre Expérimental de Recherches et d'Études pour l'Équipement (CEREEQ) ${ }^{1}$, Dakar, Senegal

${ }^{4}$ AGEROUTE-Sénégal, Fann Résidence, Dakar, Senegal

${ }^{5}$ UFR Sciences de l'Ingénieur, Université de Thiès, Thiès, Senegal

Email: ^bayeoumar.diop@ucad.edu.sn

How to cite this paper: Diop, B.O., Gbaguidi, I., Lo, P.G., Cisse, A., Sène, S. and Ba, M. (2018) Grain Size Influence on the Compaction Aptitude and the Bearing Strength of the Gravel Lateritic Soils. Geomaterials, 8, 63-76.

https://doi.org/10.4236/gm.2018.84005

Received: September 14, 2018

Accepted: October 22, 2018

Published: October 25, 2018

Copyright $\odot 2018$ by authors and Scientific Research Publishing Inc. This work is licensed under the Creative Commons Attribution International License (CC BY 4.0).

http://creativecommons.org/licenses/by/4.0/

\begin{abstract}
This study is carried out to appreciate the coarse elements influence of the gravel lateritic soils on the pavement behavior. The material involves not only the $0 / 20 \mathrm{~mm}$ granular particles considered in the specifications and on the laboratory tests, but also all of the material that is actually used in the construction sites. Geotechnical characterization was leaned on five differentiated granular classes of $0 / 20 ; 0 / 25 ; 0 / 31.5 ; 0 / 40$ and $0 / 63 \mathrm{~mm}$ diameters. The sample of $0 / 40 \mathrm{~mm}$ gets the best compaction aptitude, while that of $0 / 31.5 \mathrm{~mm}$ reaches the greatest bearing strength and a good Optimum Moisture Content. According to the requirements and its bearing strengths, the material is usable up to subbase layer and its behavior depends on the grain size.
\end{abstract}

\section{Keywords}

Granular Class, Bearing Strength, Optimum Modified Proctor (OMP), Gravel Lateritic Soils, Pavement

\section{Introduction}

The lateritic gravels are movable soil, formed in the tropical areas, and com${ }^{1}$ CEBTP: Experimental Center of Building and Public Works "Centre Expérimental de Recherches et d'Études du Bâtiment et des Travaux Publics"; AGEROUTE: Road Construction and Management Agency "Agence des travaux et de Gestion des Routes"; CEREEQ: Experimental Research and Study Center for Equipment “Centre Expérimental de Recherches et d'Études pour l'Équipement”. 
posed of pisoliths or ferruginous nodules packed in silty-clay fine matrix [1]. As noted by [2], raw laterite is mainly composed of quartz, kaolinite, goethite, hematite, gibbsite, and traces of feldspar. In geotechnical engineering, gravel lateritic soils are intensively used in road in the African tropical countries and elsewhere, notably in India and Brasilia, due to their accessibility and their affordable cost of open-pit and shallow exploitation [3]. Lateritic soils are increasingly used in road construction to reduce costs as supported by [2].

Authors who have done recent work on these contexts and this material claim the importance to change the technical approach of the analysis, either by the use of the Modulus [4] or by the treatment of the material ([2] [5] [6]). It is necessary to perform geotechnical usual tests on this material, by studying the evolution of its main properties under traffic such as gradation, plasticity, compaction characteristics and their bearing strength, to appreciate accurately their behavior ([7] [8]), in order to adapt their mechanical characteristics to the increasingly stringent traffic conditions with the view of achieving the triple challenge of state, nature and behavior.

Laterite is largely used as a road material in sub-Saharan Africa and particularly in Senegal, in compacted subgrade, subbase and base layers of the roadway construction. The usual specifications of the "Centre Expérimental de Recherche et d'Étude du Bâtiment et des travaux publics" (CEBTP) [9] allow defining the laterite requirements; according to these specifications, analyzes are carried out on samples with the maximum size of particles limited to $20 \mathrm{~mm}$. The specifications are based on the type of the pavement to construct, on the bearing strength of the subgrade and on the traffic. The handbook of the CEBTP has not been reviewed since more than 30 years, nevertheless it is still relevant, for lack of information on the traffic supported by the roads, so as to appreciate the evolution of the pavement behavior [6], despite the evolution of the traffic some final improvements are primarily operated with shallow adjustments on the treatment and are realized in the relevant handbook of the AGEROUTE (Agence des travaux et de Gestion des Routes) [10], likewise, in Ghana and in the most tropical countries [11].

In Senegal, the increasing use of the lateritic gravels has led to raise the scarcity of good materials. So, the rationalization of the existing resources requires a real knowledge of the lateritic material [12], in terms of the particle sizes distribution involvement on the bearing strength, like this study in other needful knowledge. Lateritic soils from Senegal are usually the same behavior and cannot be separated by distinctions from the nature of the parent rock [8]. However, the lateritic gravels are not sifted for pavement use on the construction sites; consequently, they involve elements often definitely higher than $20 \mathrm{~mm}$. To ensure the sustainability of the road, it is necessary to consider all of the used size materials.

That may justify the laboratory studies carried out on particles higher than 20 mm size at the "Centre Expérimental de Recherches et d'Études pour l'Équipement" (CEREEQ). It is for this purpose that this work is achieved. 


\section{Material and Methods}

This section describes the environment and the geology of the sampling pit and then explains the novelty provided to perform the geotechnical tests on range of granular classes made of gravel lateritic soils and based on standardized methods.

\subsection{Site Geography}

The lateritic deposits are called pit or quarry. In general, lateritic soils develop under highland continental conditions [13]. The mining is making by pocket excavations in the site and then the relief altitudes become uneven and ranging between 43 and $86 \mathrm{~m}$ (see Figure 1). The pit of Sindia is located in the department of Mbour into the Thies area, Sindia is the town chief of its municipality. The lateritic gravels pit extends in this field on $4793 \mathrm{~m}$ perimeter and 105.14 hectares surface, an annex is outstanding towards the other side of the road, on the west side (Figure 2).

\subsection{Geological Context}

Laterites, are used as pavement and building materials in tropical and equatorial countries of Africa and South America. They formed by chemical process, their bedrock weathering is accompanied by an impoverishment of silica and an enrichment of iron and alumina oxides-hydroxides ([6] [14]). The induration of laterite due to the presence of oxides $\left(\mathrm{Fe}_{2} \mathrm{O}_{3}\right.$ and $\left.\mathrm{Al}_{2} \mathrm{O}_{3}\right)$ after the chemical leaching, and under the alternation of wet and dry weathers, makes them heterogeneous

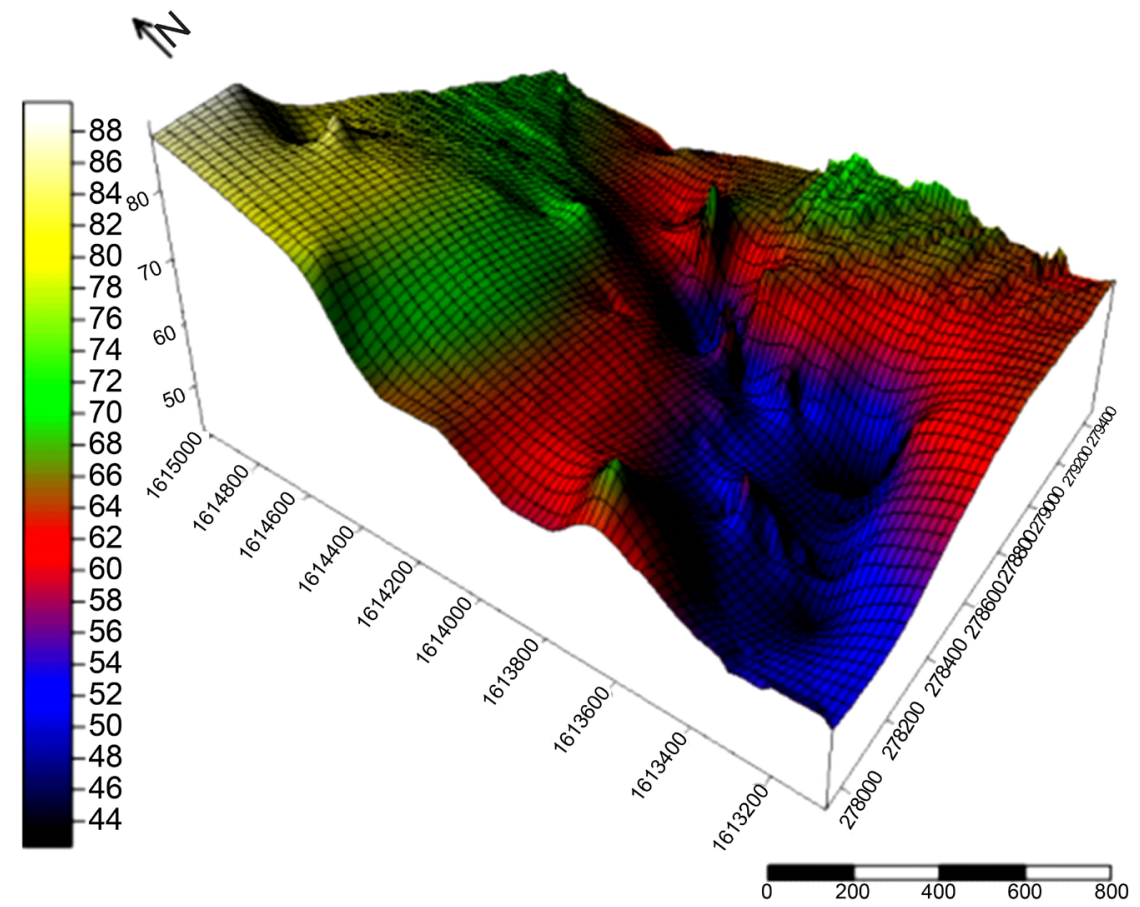

Figure 1. State of the relief on the pit (realized in June 2018, by DIOP, B. O.). 


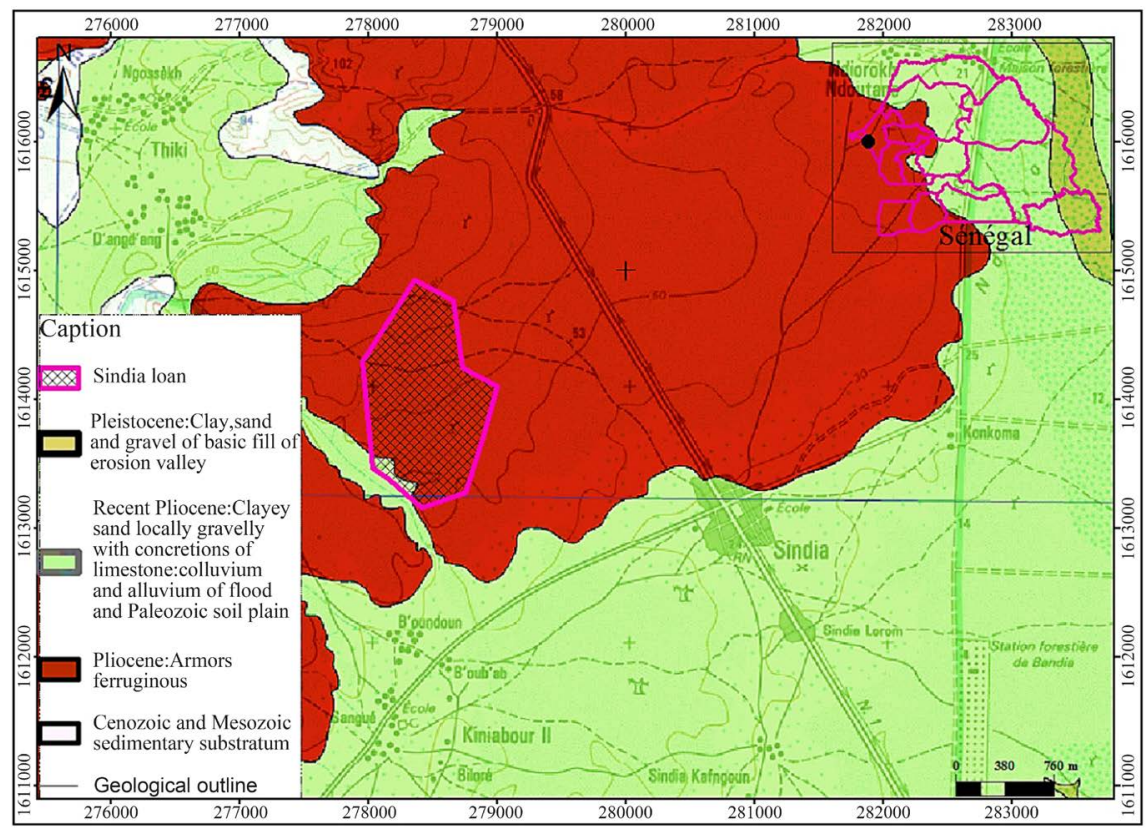

Figure 2. Geological context of the pit ([13], modified).

and anisotropic. Therefore, laterite profiles are characterized by accumulation of oxides at the upper levels and kaolinization at the lower levels [3].

The lateritic gravel soils area of Thies are mainly located in the post-rifting horst of Diass, in the western part of the Senegalese basin. The lateritic gravels pit of Sindia (Figure 2) is tied up with the Pliocene epoch [13]. The tectonic is marked by rifting faults of NE-SW general orientation and which are originated from the distension of the horst, during the Cretaceous period when the West-Africa tectonic plate separated to that of the East-America.

\subsection{Methods}

The in-situ characteristics like color, texture, structure and hardness [3] were reported before the sampling and the laboratory tests.

The laboratory studies are set on range of classes of $0 / 20 ; 0 / 25 ; 0 / 31.5 ; 0 / 40$ and $0 / 63 \mathrm{~mm}$ sizes. Beyond the distinguish classes, all of the tests were performed according to standard protocols which are locally relevant.

On the one hand, the geotechnical identification is based on the sieve analysis [15], the determination of Atterberg limits [16], and the methylene blue test [17]. On the other hand, the geotechnical characterization and mechanical tests are based on the compaction modified Proctor test [18] and on the CBR bearing test [19].

For knowing if the material can be used in subbase layer in the pavement, a subbase grading range curves were plotted according to the CEBTP specifications, and then all the cumulated percentage by weight of the passing concerning the five granular classes were also plotted to identify which of them are acceptable.

The compaction features, namely the Maximum Dry Density and the Opti- 
mum Moisture Content were determined after compaction of the material in range of moisture content (by steps of $2 \%$ by weight of not polluted water) and with the same energy of compaction $\left(2.70 \mathrm{MJ} / \mathrm{m}^{3}\right)$. It was been obtained between three and five couples of $\mathrm{X}-\mathrm{Y}$ data representing those of the respective Moisture Content-Maximum Dry Density. Hence, the Maximum Dry Density is the Y coordinate of the vertex and the Optimum Moisture Content is its $\mathrm{X}$ coordinate.

CBR test is performed with various compaction energies (10, 25 and 56 blows by free fall from a height of $457 \mathrm{~mm}$ of a hammer of $4.5 \mathrm{~kg}$ weigh, compacting a material by five layers into a mold of $152 \mathrm{~mm}$ diameter and $116 \mathrm{~mm}$ high) and putted in to soak for 96 hours [20].

\section{Results}

This section presents the main results obtained after the laboratory tests, mentions the maxima and the minima of the parameters and the global evolution of the values before giving a brief observation of the observed phenomena.

\subsection{Geotechnical Identification and Characterization of Sindia's Gravel Lateritic}

The grain size curves of five granular classes are presented in Figure 3, in comparison with the subbase grading range or the specified grading envelope.

According to Table 1, the proportion by weight of the refusal on the $16 \mathrm{~mm}$ size sieve varies from $2.89 \%$ to $36.04 \%$. This sieve is a common reference which allows getting a general overview of the analyzed granular classes, it corresponds also to the first refusal sieve in the minimum considered class of $0 / 20 \mathrm{~mm}$

Table 1. Results of the laboratory tests.

\begin{tabular}{|c|c|c|c|c|c|c|c|}
\hline \multicolumn{3}{|c|}{ Granular classes (mm) } & \multirow{2}{*}{$\begin{array}{l}0 / 20 \\
36.04\end{array}$} & \multirow{2}{*}{$\begin{array}{l}0 / 25 \\
2.89\end{array}$} & \multirow{2}{*}{$\begin{array}{r}0 / 31.5 \\
20.56\end{array}$} & \multirow{2}{*}{$\begin{array}{l}\mathbf{0 / 4 0} \\
25.06\end{array}$} & \multirow{2}{*}{$\begin{array}{l}\mathbf{0 / 6 3} \\
34.84\end{array}$} \\
\hline & & $>16 \mathrm{~mm}$ & & & & & \\
\hline $\begin{array}{l}\text { Particle size } \\
\text { analysis }\end{array}$ & $\begin{array}{l}\text { Abundance of } \\
\text { the particle sizes }\end{array}$ & $(2-16) \mathrm{mm}$ & 40.08 & 63.15 & 31.18 & 31.23 & 35.97 \\
\hline \multirow[t]{2}{*}{$N F P 94-056$} & (\% by weight) & $(0.063-2) \mathrm{mm}$ & 10.96 & 17.96 & 26.04 & 24.67 & 14.31 \\
\hline & & $<0.063 \mathrm{~mm}$ & 12.92 & 16 & 22.22 & 19,04 & 14.88 \\
\hline \multicolumn{2}{|c|}{ Determination of the Atterberg } & LL & 32.5 & 34.0 & 31.0 & 31.0 & 32.0 \\
\hline \multicolumn{2}{|c|}{ limits } & PL & 14.0 & 15.0 & 15.0 & 14.0 & 13.5 \\
\hline \multicolumn{2}{|c|}{ NF P 94-051 } & PI & 18.5 & 19.3 & 16.0 & 17.0 & 18.5 \\
\hline \multicolumn{8}{|c|}{ Determination of the Methylene } \\
\hline \multicolumn{7}{|c|}{$N F \mathrm{P} 94-068$} & 0.20 \\
\hline Modified & Proctor test & $\operatorname{MDD}^{\mathrm{a}}\left(\mathrm{kN} / \mathrm{m}^{3}\right)$ & 18.9 & 19.5 & 19.0 & 19.6 & 19.2 \\
\hline$N F$ & $94-093$ & $\mathrm{OMC}^{\mathrm{b}}(\%)$ & 11.67 & 11.85 & 11.40 & 12.26 & 10.71 \\
\hline $\begin{array}{r}\text { 4-day soa } \\
\text { NF }\end{array}$ & $\begin{array}{l}\text { ed CBR test } \\
94-078\end{array}$ & $\begin{array}{c}\text { Material Compacted at } \\
95 \% \text { of the OMP }\end{array}$ & 53 & 74 & 75 & 70 & 63 \\
\hline
\end{tabular}

a. MDD: Maximum Dry Density ( $\gamma \mathrm{d}$ max); b. OMC: Optimum Moisture Content (WOPM). 


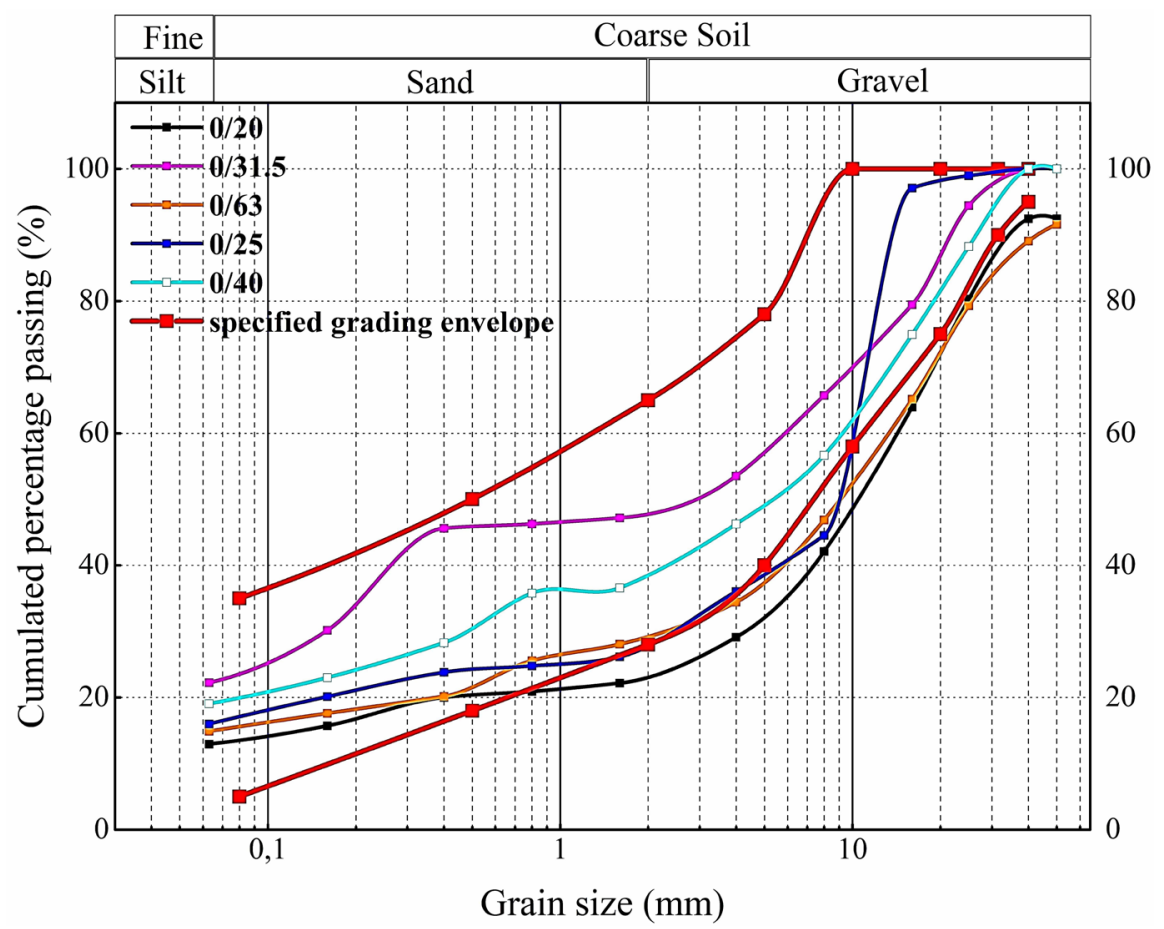

Figure 3. Grain size distribution curves with respect to the subbase grading range of the CEBTP.

The refusal grains ranging between $2 \mathrm{~mm}$ and $16 \mathrm{~mm}$ size, are in the range of $31.18 \%$ and $63.15 \%$ by weight. The refusal on the sieve of $2 \mathrm{~mm}$ let us to draw a line between the gravelly, and the sandy-silty-clayey soils.

The refusal particles ranging between $0.063 \mathrm{~mm}$ and $2 \mathrm{~mm}$ size are between $10.96 \%$ and $26.04 \%$ by weight. The $0.063 \mathrm{~mm}$ mesh set apart fines from the sand.

In other words, fines are clay and silty soils (particles lower than $0.063 \mathrm{~mm}$ size) vary from $12.92 \%$ to $22.22 \%$ by weight.

Particle size distribution curves of all the granular classes analyzed contain more coarse particles than finer elements as presented in Figure 4.

The Atterberg limits make the calculation of the plasticity index (PI) possible for these various size samples; the plasticity index value ranges between 16.0 and 19.3 (Figure 5), implies a plastic material [9]; PI (see Equation (1)) is ranging between 15 and 40 .

$$
P I=\omega l-\omega p
$$

The trend of the plasticity is inverse to that of the fines; granular classes which contain less fines are more plastics.

The methylene blue test makes the calculation of the soil methylene blue value $(\mathrm{MBV})$ possible. For the analyzed samples, MBV varies from 0.17 to $0.32 \mathrm{~g} / 100 \mathrm{~g}$ (see Table 1). The results of the laboratory tests reveal that the material is slightly sensitive to water according to [21].

The results of the modified Proctor test disclose that the samples have a maximum dry density (MDD) ranging between 18.9 and $19.6 \mathrm{kN} / \mathrm{m}^{3}$, the lowest 


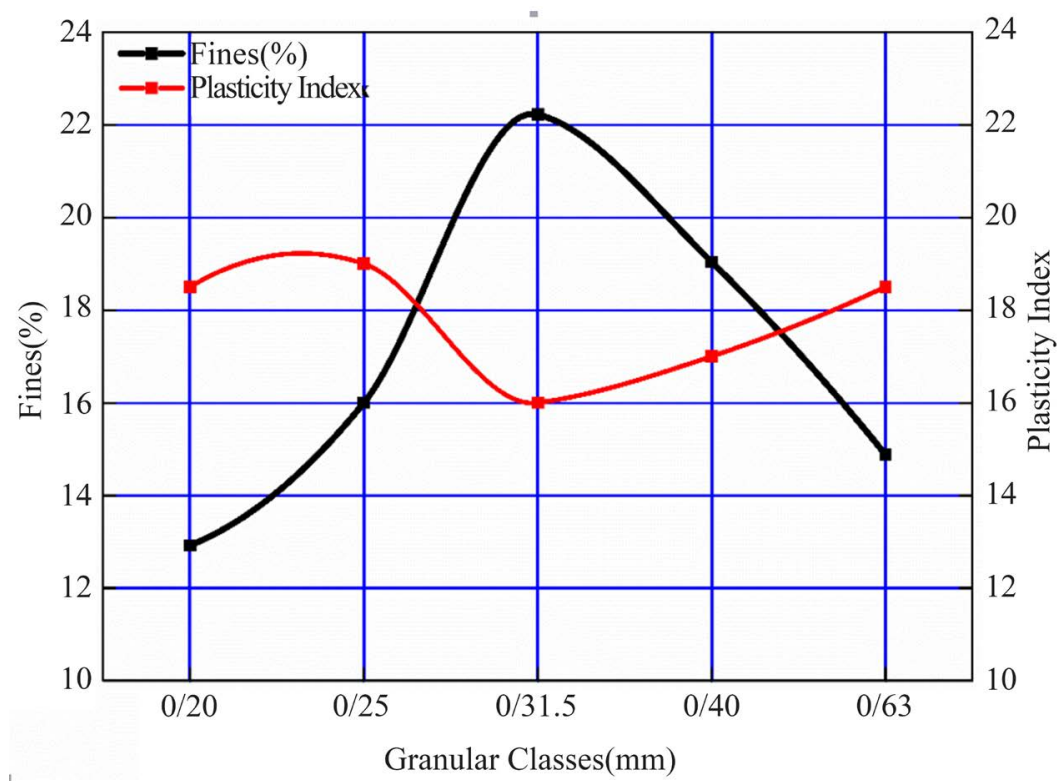

Figure 4. Evolution of fines in comparison with the plasticity nature.

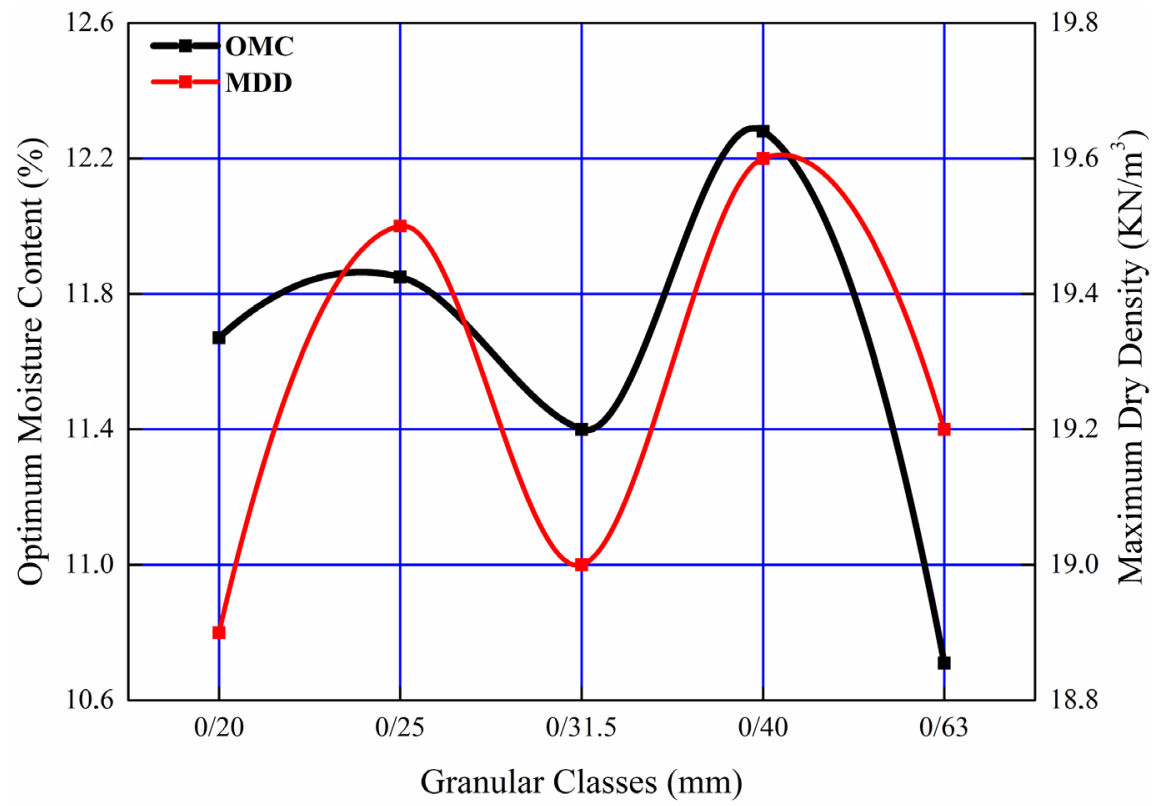

Figure 5. Compacting characteristics of the modified Proctor Test.

value of $18.9 \mathrm{kN} / \mathrm{m}^{3}$ is got by the granular class of $0 / 20 \mathrm{~mm}$ size. While the greatest value of $19.6 \mathrm{kN} / \mathrm{m}^{3}$ is reached by the class of $0 / 40 \mathrm{~mm}$ size (Table 1 ).

The CBR index ranges between 53 and 75 . The value of 53 is reached by the $0 / 20 \mathrm{~mm}$ standard class, and that of 75 with the $0 / 31.5 \mathrm{~mm}$ class (Table 1 ).

These results are near to the obtained results by [22], on the same site.

\subsection{Discussion}

The results analyzed above are discussed in this section to come out and then stand out their usefulness on the pavement constructions by comparing the re- 
sults with the previous studies and the standards in order to enhance the roadways behavior.

\subsubsection{Granularity Influence on the Compaction Aptitude}

Among the granular classes analyzed, the $0 / 31.5 \mathrm{~mm}$ and that of $0 / 40 \mathrm{~mm}$ classes are the most consistent with the subbase grading range or the specified grading envelope of the CEBTP (Figure 3).

All the granular classes analyzed are lateritic gravel soil, because they contain both percentages of fines ranging between $12 \%$ and $35 \%$ by weight and a skeleton or coarser particles (higher than $2 \mathrm{~mm}$ size) always superior to $50 \%$ by weight in accordance with [23]. The lateritic soil of Sindia presents a strong cohesion due to the compaction effect, by cementing the soil, this lateritic material of Sindia has therefore a "ductile" behavior [22].

\section{Grading characteristics}

The grading characteristics are determined as follows:

Uniformity Coefficient

$$
\mathrm{Cu}=\frac{\mathrm{D}_{60}}{\mathrm{D}_{10}}
$$

Equation (2) permits to express the extent of the Grain size curves, where:

$\mathrm{D}_{60}=$ effective particle diameter corresponding to $60 \%$ by weight of the passing.

$D_{10}=$ effective particle diameter corresponding to $10 \%$ by weight of the passing.

According to the value of the coefficient of uniformity, we distinguish two classes (Table 2).

\section{Curvature coefficient}

$$
\mathrm{Cc}=\frac{\left(\mathrm{D}_{30}\right)^{2}}{\mathrm{D}_{60} \times \mathrm{D}_{10}}
$$

Equation (3) allows describing the shape of the granulometric curves, where:

$D_{30}=$ effective diameter of the particles which correspond to $30 \%$ by weight of the passing.

When certain conditions on $\mathrm{Cu}(\mathrm{Cu} \geq 4)$ and $\mathrm{Cc}(1 \leq \mathrm{Cc} \leq 3)$ are satisfied the soil is well-graded in other words its curve tends to become continuous and flat, without prevalence of any particular fraction (see Figure 3). That indicates, there are coarse particles which their intergranular spaces are filled with clay, sand and silt [3]. The well graded soils are naturally dense deposits and can reach a high CBR bearing index, if their fines are not very organic or composed of clay. However, the poorly or uniformly graded [24] curves show that the material contain just one or two categories of soil among the clay, silt, and sand particles. They are curves which are not flat and tend to have an upward gradient evolution.

Thus, according to Table 3, the granular classes analyzed are well graded and the high value of the $\mathrm{Cu}$ indicates that the soil contains range of particle sizes. 
Table 2. Soil granulometry classes.

\begin{tabular}{cc}
\hline Coefficient of uniformity & Type of curve \\
\hline $\mathrm{Cu}<4$ & Poorly or uniformly graded \\
$\mathrm{Cu} \geq 4$ & well graded \\
\hline
\end{tabular}

Table 3. Grading characteristics.

\begin{tabular}{ccccccc}
\hline Granular classes $(\mathrm{mm})$ & & $0 / 20$ & $0 / 25$ & $0 / 31.5$ & $0 / 40$ & $0 / 63$ \\
\hline \multirow{2}{*}{ Granular characteristics } & $\mathrm{Cu}^{\mathrm{a}}$ & 750 & 500 & 300 & 450 & 750 \\
& $\mathrm{Cc}^{\mathrm{b}}$ & 67.50 & 45.00 & 0.19 & 1.38 & 6.66 \\
\hline
\end{tabular}

a. Uniformity Coefficient; b. Curvature Coefficient.

Only the curve of the $0 / 40 \mathrm{~mm}$ granular class satisfies the well graded conditions of the $\mathrm{Cu}$ and the $\mathrm{Cc}$ requirements, the $0 / 31.5 \mathrm{~mm}$ class is closer to the previous class than the rest, and then become the second granular class of all the five in terms of grading features. The well graded class has intergranular voids filled by other smaller particles and thus, this can improve the bearing strength as noted in [11].

Overall, fines are considered to enhance the plasticity, notably in [25]. Nevertheless, the results indicate the opposite to this (Figure 5) and confirm that the contribution of the fines in the plasticity of the lateritic soils is not inherent [11]. This depends on the organic or mineral origin of the fines or to the sensitive of water due to the presence of argil which is different from the kaolinite. The plastic indexes obtained in Table 1 indicate a low plasticity, hence, a mineral origin and the presence of kaolinite in the ferruginous soils.

Though, the identification parameters and the CBR index did not vary enough at the time, the compaction characteristics of the lateritic gravels of Sindia are slightly inflected compared to the former researches, in particular, those of [6], this can be either related to the heterogenous quality in the pit as aforementioned and likewise in India [5], or to the excavation targeted on the good quality of materials at the first time.

To cope with this drop-in quality, different solutions were sought, either by blending laterites with varying proportion of sand, limestone, and cement; [6] and [2] respectively, or even its substitution by basalt or limestone [26]. However, these results are relatively variable and sometimes mediocre behaviors for the admixture alternatives, and expensive costs that go with an increasingly depletion of the resource for the substitution alternative by basalt which are more resistant and sustainable for the pavement construction.

Indeed, particles have to be resistant because they can get a high void index after compaction. After loading, the material breaks up causing an increase in void ratio and loss of strength [12]. The compaction leads to a reorganization of the particles, a disaggregation of the clods, an increase of the specific surface subsequent to the fine grains which ensure cohesion, and primarily increase the 
compactness of the material at short term before their late and progressive breaking down at long term, due to the repeated loading of the traffics.

Figure 5 shows the compacting characteristics: Maximum Dry Density ( $\gamma \mathrm{d}$ $\max$ or MDD), and the Optimum Moisture Content ( $\mathrm{OMC}$ or $\left.\mathrm{W}_{\mathrm{OPM}}\right)$. Their evolution is similar, for the $0 / 31.5$ and the $0 / 40 \mathrm{~mm}$ classes and inverse for the rest, in regards to them relative value. Between these two classes, the first is less sensitive that the second to water. Even so the two curves of the considered parameter are the same wavy trend. All the classes reach a MDD higher than 18 due to the presence of iron minerals in the laterite materials, which can increase the MDD and therefore the CBR index [24].

The low grade of the Maximum Dry Density is getting by the standardized class of $0 / 20 \mathrm{~mm}$ diameters; the best compactness is reached by the $0 / 40 \mathrm{~mm}$ class which gets the highest of both moisture content and maximum dry density. But the CBR is sensitive to water [20].

\subsubsection{Granularity Influence on the Bearing Strength}

Figure 6 displays the evolution of four day soaked CBR index after compaction at $95 \%$ of the OMP in comparison with the MDD of the granular classes. The 0/20 $\mathrm{mm}$ standardized class has the lowest CBR index values and OMC, while the $0 / 31.5 \mathrm{~mm}$ has the highest CBR index value and lower percentage of WOPM than the rest after the class of $0 / 20 \mathrm{~mm}$ diameters. The $0 / 40$ have the highest WOPM and the second best CBR index, so it presents the most consistent evolution, thus the best compaction characteristics in spite of its important moisture content (see Figure 5).

CBR is an important parameter in pavement design [27] to assess the durability and the load strength.

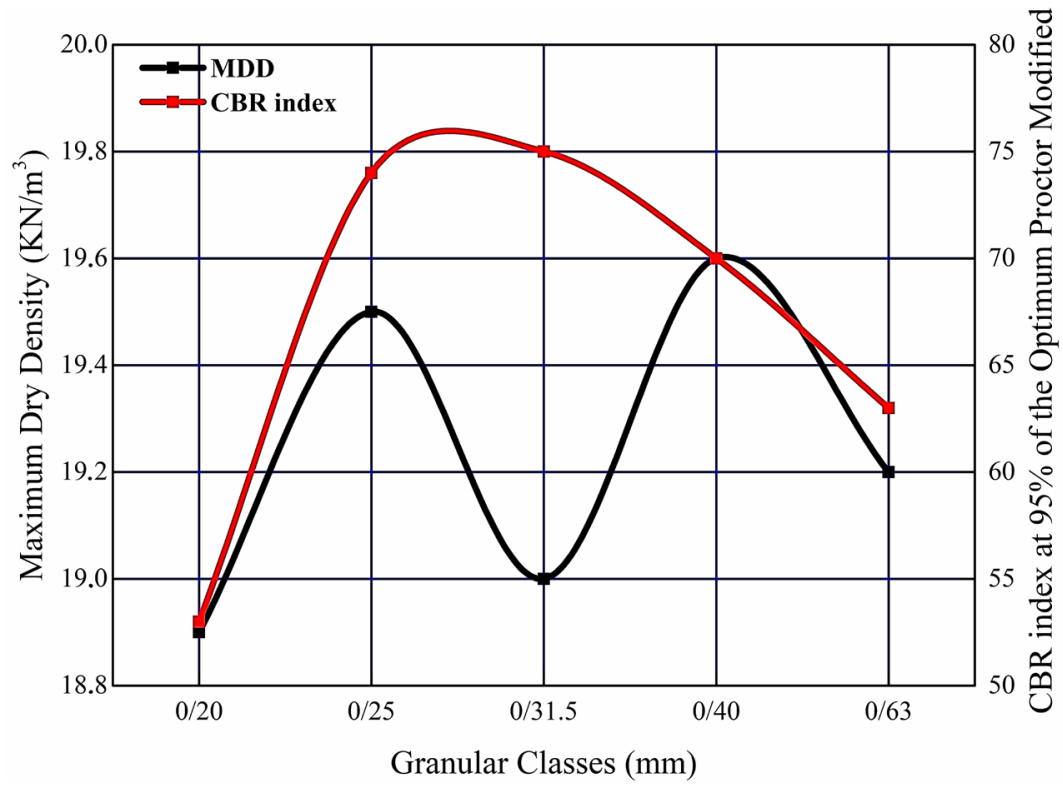

Figure 6. Evolution of the CBR index comparatively with the maximum dry density of the lateritic gravel samples. 
The soil is becoming denser during the compaction. It gradually changes from a loose to a dense state. Air void between the coarse grains tends to be reduced and filled by fine particles generated by the breaks material [27]. As it is shown that between the five classes, the well graded by its coefficient of uniformity contain more fines, and can get the best CBR index, it is that of $0 / 31.5 \mathrm{~mm}$ diameters. Here, we can approve that the compacting produces additional fines to fill the gravel/gravel and gravel/sand voids, thus enhancing the resistance to swell [11] and the bearing strength, thus the sustainability of the pavement.

The characteristics of the lateritic soils vary considerably based on their mineralogical composition, microstructure of soil particles, climate condition, parent rock and the degree of laterization [5]. Thus, it is confirmed by our different results that the laterites behavior varies according to their particle sizes.

\subsubsection{Use of the Sindia Gravel Lateritic Soils in Pavement}

The specifications of the CEBTP allow defining the use conditions of the raw lateritic gravels in pavement. Nevertheless, the required conditions concern only the $0 / 20 \mathrm{~mm}$ granular class on which are applied the standard procedures of the modified Proctor and the CBR tests. After immersion the CBR decrease considerably and this is more important for the first three day [20], from which it is important to consider the 4 days soaked CBR, to anticipate on the flood hazard.

If we consider the only reference of $0 / 20 \mathrm{~mm}$ size, this material can be used in their raw state, in the road such as subbase and not as a base layer, for the traffics ranging from $\mathrm{T} 1$ to $\mathrm{T} 5$ (Table 4). Because firstly the maximum dry density of $18.9 \mathrm{kN} / \mathrm{m}^{3}$ is not between the values of 21.0 to $23.0 \mathrm{kN} / \mathrm{m}^{3}$, and afterwards the $\mathrm{CBR}$ index equal to 53 is definitely lower than the minimal required index of 80 , for the base layer.

Laterite has high mechanical properties compared to sand, silt and clay due to the presence of the coarser elements. These materials are gritty and are sparsely

Table 4. Geotechnical parameters of the $0 / 20 \mathrm{~mm}$ granular class in relation to CEBTP specifications (traffics $>$ T2).

\begin{tabular}{|c|c|c|c|}
\hline \multirow{2}{*}{ Geotechnical parameters } & \multirow{2}{*}{$0 / 20 \mathrm{~mm}$ class } & \multicolumn{2}{|c|}{ CEBTP specifications (1984) } \\
\hline & & Subbase layer & Base layer \\
\hline $\begin{array}{c}\text { Particles } \leq 0.080 \mathrm{~mm} \text { size } \\
\text { (\% by weight) }\end{array}$ & 13.5 & $5-30$ & $5-25$ \\
\hline Liquid limit (LL) & 32.5 & $<40$ & $<35$ \\
\hline Plasticity index (PI) & 18.5 & $5-22$ & $5-20$ \\
\hline $\begin{array}{l}\text { Methylene blue values of the soil } \\
\qquad(\mathrm{MBV})(\mathrm{g} / 100 \mathrm{~g})\end{array}$ & 0.17 & $<5$ & $<5$ \\
\hline $\begin{array}{l}\text { Maximum dry density } \\
\qquad\left(\gamma \mathrm{d} \max \left(\mathrm{kN} / \mathrm{m}^{3}\right)\right.\end{array}$ & 18.9 & $18.0-20.0$ & $21.0-23.0$ \\
\hline CBR index at $95 \%$ of the OMP & 53 & $30-60$ & $\geq 80$ \\
\hline $\begin{array}{c}\text { Classification in } \\
\text { (LCPC/SETRA, 2000) }\end{array}$ & & B4 & \\
\hline
\end{tabular}


plastic; this plasticity may explain these CBR values [24], hence it is important to perform the plasticity test at the first time.

If we use the required specifications presented in the [9] to evaluate our results, we can record that the five analyzed granular classes met the criteria for be use up to the foundation layer, under all of the considered traffics (T1 to T5).

\section{Conclusions}

Laboratory tests allowed identifying and characterizing the Sindia lateritic gravel samples of five granular classes of $0 / 20 ; 0 / 25 ; 0 / 31.5 ; 0 / 40$ and $0 / 63 \mathrm{~mm}$ sizes. The results show that the best compaction aptitude is obtained by the class of $0 / 40 \mathrm{~mm}$ size, while that of $0 / 31.5 \mathrm{~mm}$ reaches the greatest value of the bearing strength (soaked CBR index of 75).

According to the use standard procedures and the specifications, only applied to the granular class of $0 / 20 \mathrm{~mm}$, the gravel lateritic soils of Sindia can be used in subbase layer under traffics higher than T5, because the CBR index is higher than 60 for the most analyzed classes. However, the maximum dry density and the CBR index values obtained are less than the required values in base layer which are 21.0 to $23.0 \mathrm{kN} / \mathrm{m}^{3}$ and 80 respectively, unless it is for a T1 traffic which required $\mathrm{CBR} \geq 60$ according to [9]. Therefore, it is well noted that there is a real influence of the particle sizes on the gravel lateritic soils behavior.

This study is part of a current project in CEREEQ, which promote local materials; hence, other publications are still waited for further develop and broaden these studies to confirm the recording and giving new opportunities from the pit to the construction site.

\section{Acknowledgements}

The authors would like to thank the Experimental Research and Study Center for Equipment (CEREEQ) of Dakar for funding this research, and the National Institute of soil Science (INP) for technical assistance, particularly Dr Macoumba Loum and Alioune Badara Dieye.

\section{Conflicts of Interest}

The authors declare no conflicts of interest regarding the publication of this paper.

\section{References}

[1] Autret, P. (1980) Contribution à l'étude des graveleux latéritiques traités au ciment. ENPC, Paris.

[2] Mengue, E., Mroueh, H., Lancelot, L. and Medjo, R. (2017) Physicochemical and Consolidation Properties of Compacted Lateritic Soil Treated with Cement. Soils Found, 57, 60-79. https://doi.org/10.1016/j.sandf.2017.01.005

[3] Kasthurba, A.K., Santhanam, M. and Mathews, M.S. (2007) Investigation of Laterite Stones for Building Purpose from Malabar Region, Kerala State, SW India-Part 1 : Field Studies and Profile Characterization. Construction and Building Materials, 21, 
73-82. https://doi.org/10.1016/j.conbuildmat.2005.07.006

[4] Fall, M., et al. (2011) Evolution of Lateritic Soils Geotechnical Parameters during a Multi-Cyclic OPM Compaction and Correlation with Road Traffic. Geomaterials, 1, 59-69. https://doi.org/10.4236/gm.2011.13010

[5] Biswal, D.R., Sahoo, U.C. and Dash, S.R. (2016) Transportation Geotechnics Characterization of Granular Lateritic Soils as Pavement Material. Transp. Geotech, 6, 108-122. https://doi.org/10.1016/j.trgeo.2015.10.005

[6] Ndiaye, M., Magnan, J.-P., Cissé, I. K. and Cissé, L. (2013) Étude de l' amélioration de latérites du Sénégal par ajout de sable. BLPC, 280-281, 123-137.

[7] Ba, M., Fall, M., Samb, F., Sarr, D. and Ndiaye, M. (2011) Resilient Modulus of Unbound Aggregate Base Courses from Senegal (West Africa). Open Journal of Civil Engine, 1, 1-6. https://doi.org/10.4236/ojce.2011.11001

[8] Fall, B.-I.M., Tisot, J.-P. and Cisse, I.K. (1994) Specifications for Road Design Using Statistical Data, an Example of Laterite or Gravel Iateritic Soils from Senegal. Bulletin of the International Association of Engineering Geology, 50, 17-35. https://doi.org/10.1007/BF02594953

[9] CEBTP (1984) Guide pratique de dimensionnement des chaussées pour les pays tropicaux. 2nd Edition, Ministère de la Coopération, France.

[10] AGEROUTE (2015) Catalogue de structures de chaussées neuves et Guide de dimensionnement des chaussées au Sénégal. AGEROUTE-Senegal, Senegal.

[11] Frempong, E.M. and Tsidzi, K.E.N. (1999) Blending of Marginally Suitable Tropical Sub-Base Materials for Use in Base Course Construction. Construction and Building Materials, 13, 129-141. https://doi.org/10.1016/S0950-0618(99)00015-X

[12] Samb, F., Ba, M., Fall, M. and Berthaud, Y. (2013) Étude du comportement cyclique de graveleux latéritiques du Sénégal. Collect. ÉCOMATERIAUX DE CONSTRUCTION: PILIER DE LA CROISSANCE VERTE EN AFRIQUE, 10-12 June 2013, Ouagadougou, 4.

[13] Roger, J., et al. (2009) Notice explicative de la cartographie multicouches à 1/50 000 et 1/20 000 de la zone d'activité du Cap-Vert. Ministère des Mines, de l'Industrie et des PME, Direction des Mines et de la Géologie, Dakar.

[14] Zondjé, P.B.B. (2008) Caractérisation des sols latéritiques utilisées en construction routière: cas de la région de l'Agneby (Côte d'Ivoire). Ecole des Ponts ParisTech, Paris.

[15] AFNOR (1996) NF P 94-056 Soil: Investigation and Testing-Particle Size Analysis-Dry Sieving Method after Washing. LCPC, Paris, 15.

[16] Afnor, N.F. (1993) P 94-051 Soil: Investigation and Testing-Determination of Atterberg Limits-Liquid Limit Test Using Casagrande Apparatus-Plastic Limit Test on Rolled Thread. LCPC, Paris, 14.

[17] Afnor, N.F. (1998) P 94-068 Soil: Investigation and Testing-Measuring of the Methylene Blue Adsorption Capacity of a Rocky Soil-Determination of the Methylene Blue of a Soil by Means of the Stain Test. LCPC, Paris, 7.

[18] Afnor, N.F. (1999) P 94-093 Soils: Investigation and Testing-Determination of the Compaction Characteristics of a Soil-Standard Proctor Test-Modified Proctor test. LCPC, Paris, 15.

[19] Afnor, N.F. (1997) P 94-078 Soils: Investigation and Tests-CBR after Immersion-Immediate CBR-Immadiate Bearing Ratio-Measurement on Sample Compacted in CBR Mould. LCPC, Paris, 9.

[20] Fall, M., Ba, S., Sarr, D., Ba, M. and Ndiaye, M. (2011) An Alternative Method to the 
West African Compaction (WAC) Test Procedure. Earth \& Environmental Sciences, 1, 25-27.

[21] LCPC/SETRA (2000) Réalisation des remblais et des couches de forme. 2nd Edition.

[22] Ndiaye, C. and Berthaud, Y. (2018) Identification of a Cam Clay Model through Shear-Box and Oedometer Tests. Application to Lateritical Soils from Senegal (West Africa). Earth \& Environmental Sciences, 8, 1-13.

[23] AFNOR (1992) NFP 11-300: Exécution des terrassements-Classification des matériaux utilisables dans la construction des remblais et des couches de forme d'infrastructures routières. LCPC, Paris, 21.

[24] Niakhate, E.H.B.M., Tamba, S., Ba, M., Dione, A. and Ndoye, I. (2016) Soil Subgrade's Characterization and Classification of Thies (Senegal, West Africa) on a Radius of 2.5 Kilometers along Five Roads. 1-17.

[25] Tardy, Y. (1993) Petrology of Laterites and Tropical Soils. Masson, Paris.

[26] Ba, M. (2012) Comportement mécanique sous sollicitations cycliques de granulats quartzitiques de Bakel-Comparaison avec des matériaux de référence du Sénégal et d'Amérique (USA). Université Cheikh Anta Diop.

[27] Fall, M., Ba, S., Sarr, D., Ba, M. and Ndiaye, M. (2011) An Alternative Method to the West African Compaction (WAC) Test Procedure. Geomaterials, 1, 25-27. https://doi.org/10.4236/gm.2011.12004 